\title{
Experimentação Investigativa e llustrativa: um estudo sobre a efetividade no ensino de Geociências
}

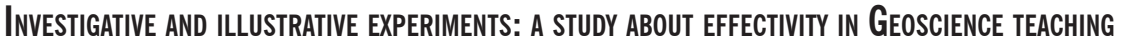

\author{
Pedro Leverger Costa ${ }^{1}$, Evelyn Aparecida Mecenero Sanchez ${ }^{2}$ \\ 1- Faculdade UNB de Planaltina, Área Universitária 01, Vila Nossa Senhora de Fátima, Planaltina, DF. pedrol.costa91@gmail.com \\ 2- Faculdade UnB de Planaltina, Universidade de Brasília \& Instituto de Ciência e Tecnologia, Universidade Federal dos Vales do \\ Jequitinhonha e Mucuri, Rodovia MGT-367, km 583, n.5000, Alto da Jacuba, Diamantina, MG, evelyn.sanchez@ict.ufvjm.edu.br
}

ABSTRACT: The importance of classes involving different activities in order to fill the gaps left by traditional classes is increasingly recognized. An alternative to the traditional methods is the use of experiments, which, among various pragmatic classifications, can be divided into investigative experiments, in which the activity is developed prior to the theoretical content; and illustrative experiments, which are held after the theoretical content, seeking to prove some studied phenomenon. In the context of Geosciences, classes may include topics common to everyday aspects, but not always easy to be perceived, as well as abstract subjects, due to their spatial and/or time scale, and in this sense, experiments become excellent teaching tools. In the present study the effectiveness of illustrative and investigative experiments against a daily theme (erosion) and other abstract (embossing) were analyzed. The study showed that an illustrative experiment, inserted after the theory, was more effective both when it came to abstract, as when the subject was routine, while investigative experiment was more effective at keeping students' attention and discussions about theories, regardeless of whether it was more familiar or an abstract theme.

\section{Manuscrito:}

Recebido: 24/08/2016

Corrigido: $31 / 08 / 2016$

Aceito: 20/10/2016

Citation: Costa P.L., Sanchez E.A.M.. 2016 Experimentação Investigativa e llustrativa: um estudo sobre a efetividade no ensino de Geociências. Terræ Didatica, 12(3):220-230. < http:// www.ige.unicamp.br/terraedidatica/>.

Keywords: Experimentation, practical classes, teaching strategies, abstract subjects, familiar subjects.

\section{Introdução}

Experimentações figuram como uma importante ferramenta no ensino de Ciências, uma vez que podem apresentar papeis múltiplos, atuando desde o processo de aprendizagem, até a interação entre alunos, adquirindo, ainda papel sócio-técnico-cognitivo, como apontado por Giordan (1999). Dois tipos de experimentações são classicamente tratados durante o ensino superior na área de licenciatura em diferentes Ciências, sendo a experimentação investigativa e a ilustrativa (Delizoicov 1991, Giordan 1999, Francisco et al. 2008). Enquanto a experimentação investigativa é realizada anteriormente à teoria, a outra, ilustrativa, é realizada após a teoria. Apesar de ser pouco utilizada (Galiazzi et al. 2001), a experimentação não requer materiais caros ou de difícil acesso e não há necessidade de espaços específicos para a sua realização (de Oliveira \& Soares 2010) possibilitando suas aplicações em sala de aula de forma fácil e acessível.
No entanto, cabe a pergunta de qual seria o melhor tipo de experimentação, já que os dois tipos são defendidos e utilizados por professores em todos os níveis de Ensino e defendidos na literatura (Leite 2001, Laburú et al. 2003, Oliveira \& Soares 2001 e outros). Partindo de tal questionamento, julgou-se necessário estudar qual tipo de experimentação é mais eficaz no aprendizado dos alunos e analisar a finalidade de cada um. Afinal, amadurecer o conhecimento sobre o papel da experimentação, através da melhor compreensão dos mecanismos evolvidos e dos efeitos desta prática sobre a aprendizagem, permitirá aplicá-la de forma mais efetiva e como uma alternativa ao ensino tradicional.

Por meio das discussões realizadas em cursos de graduação de Licenciatura, conhecimentos adquiridos através da literatura e observação da qualidade do aprendizado dos alunos durante as práticas vivenciadas, fica explícito que o Ensino Tradicional, onde o aluno necessita ser atualizado, reproduzir e armazenar conhecimentos impostos 
a ele, entre outros processos (Mizukami 1986), por si só, nem sempre traz resultados positivos no que diz respeito à sua aprendizagem, apesar de que ainda sejam necessárias pesquisas especificamente direcionadas a esse tema que embasem tal posição. Nesse tipo de ensino, o aluno que adquire conhecimento, na realidade só memoriza definições e regras que lhe são dadas como verdade incontestável e ainda apresentam compreensão parcial do tema (Mizukami 1986).

Ainda de acordo com a autora, o professor é o centro da aula e os alunos são apenas espectadores reprodutores de conceitos tornando-os não pensantes. Partindo desse ponto, os autores (Laburú et al. 2003, p. 248) indicam:

(...) uma proposta metodológica pluralista para a educação científica, pois parte do pressuposto de que todo processo de ensino-aprendizagem é altamente complexo, mutável no tempo, envolve múltiplos saberes e está longe de ser trivial.

Uma forma alternativa que torna possível alcançar os objetivos citados, facilitar o aprendizado do aluno e ainda complementar as aulas teóricas é o uso de diferentes recursos didáticos (Laburú \& Zômpero 2003) e, entre eles, pode-se citar a experimentação. Esse tipo de atividade permite que o aluno visualize algum fenômeno, discuta e analise a relação do conteúdo teórico com situações cotidianas. O uso de atividades práticas, tal como experimentos, também tem o papel de permitir uma aproximação e diálogo entre alunos e professores, levando à discussão de melhores estratégias de ensino para a melhor compreensão dos processos científicos (Rosito 2000). Além disso, segundo o PCN do Ensino Fundamental para o terceiro e quarto ciclo, a experimentação permite uma reflexão sobre o tema que vem sendo estudado, além de fornecer espaço para a construção de ideias.

Para Compiani (2005), a escola não considera o aluno como uma pessoa dentro de um contexto com um espaço onde vive e com experiência social. Apesar de vários conteúdos fazerem parte do cotidiano e influenciarem na vida dos alunos, os professores, de modo geral, não mostram essa relação, e é de senso comum que os alunos não sintam interesse pelas matérias que não veem necessidade em saber tal assunto. Para o autor, o papel da escola é dar sentido às informações que podem ser adquiridas no ambiente original do aluno produzindo uma ligação entre o cotidiano e o conhecimento científico. Com o uso de experimentação, essa maneira de ensinar Ciências pode ser abolida ou, pelo menos, amenizada, pois a experimentação é "uma atividade que verifica hipóteses (...) que exige a observação, implica em reflexão e compreensão dos fenômenos, num processo que visa entender a realidade." (Del Pozzo 2010, p. 27), além de permitir discussões sobre o tema das aulas (Vasconcelos et al. 2015). Com isso, o aluno será capaz de observar o fenômeno não só no momento do experimento, mas também fazer uma ligação com seu cotidiano compreendendo-o e sentindo-se parte do sistema ao seu redor.

Embora possa ser uma promissora ferramenta de ensino e uma ótima forma de fazer com que o aluno aprenda um conteúdo, a experimentação não pode ser tida como forma única de aprendizado (Viviani \& de Oliveira 2001). Por esta razão, torna-se necessário o uso do material didático como forma de acompanhar o ensino. Ainda segundo as autoras, com base em outros autores, o uso de uma experimentação não é a saída certa para todo tipo de conteúdo, pois existem restrições acerca das experimentações. Além disso, o papel dos experimentos pode ser subestimado ou mal aplicado. Esta afirmativa é percebida nos próprios PCNs, onde é colocado que utilizar experimentação significa "o professor realiza uma demonstração para sua classe, e a participação dos estudantes reside em observar e acompanhar os resultados." (Brasil 1997, p.122), ou seja, se mal interpretado, o experimento adquire o mesmo caráter das aulas tradicionais.

Baseada no exposto, uma grande ênfase é dada por parte de docentes da graduação superior quando se fala em experimentação em sala de aula como parte da forma de ensino. Muitos desses docentes defendem a grande importância da experimentação antes da teoria, para que o aluno se interesse sobre o que será abordado e que, juntamente com o professor e os colegas da sala, construa o conhecimento a partir da observação da simulação do processo natural demonstrado (Wilsek 2008). Por outro lado, há aqueles que defendem o uso dessa prática após o ensino teórico, para que o aluno reforce e discuta o fenômeno demonstrado com base no que aprendeu e compreenda como acontece o evento simulado (Giordan 1999). De um jeito ou de outro, o experimento é bem visto pelos alunos e professores, pois, além de motivar os estudantes, permite uma alternativa lúdica de ensino (Giordan 1999). Ainda, a experimentação não requer materiais caros, sendo possível desenvolver atividades 
com recursos baratos e de fácil acesso, além de nem sempre haver necessidade de laboratórios para certos experimentos (de Oliveira \& Soares 2010), somente cuidados especiais para não sujar a sala ou danificar carteiras e outros materiais que não envolvam o experimento.

De acordo com a literatura (Leite 2001, Laburú et al. 2003, de Oliveira \& Soares 2001 e outros), dois tipos de experimentação podem ser abordados em sala de aula. A primeira experimentação é de natureza investigativa, onde o experimento é realizado para dar início à aula. Essa aula tem sua base teórica fundamentada no experimento realizado, ou seja, o conhecimento é construído juntamente entre professor e alunos permitindo discussão de teorias e pensamento crítico (Hartwig 2008), além da demonstração do fenômeno instigar curiosidade e questionamentos nos alunos. Ao utilizar experimentações investigativas, o aluno sai da posição de "plateia" e torna-se ativo na construção de seu conhecimento (Azevedo 2004). Já a experimentação ilustrativa tem como estratégia a realização da experimentação nos últimos momentos da aula para comprovar o estudado (Giordan 1999, Hartwig 2008), além de permitir ao aluno compreender o demonstrado na aula teórica.

Percebendo o emprego destes experimentos em outras áreas de ensino de Ciências, nota-se que o ensino de Geociências também pode contar com o uso das práticas e deve ser mais utilizado já que a maior parte de suas abordagens são custosas de serem observadas. Junto com este fato, o mau uso ou uso exacerbado de recursos naturais e a necessidade de conscientização do cuidado com o planeta (Bacci 2009), que pode partir das escolas, justifica a utilização do ensino de Geociências como conteúdo foco do estudo. Segundo Bacci (2009), como consequência da extração de recursos naturais, a sociedade teve a necessidade de tomar maior conhecimento sobre as interferências desta extração no meio ambiente a partir da educação ambiental. A autora afirma que, para que seja construída uma Educação Ambiental Crítica, deve-se divulgar o conhecimento geológico, já que este conhecimento abrange a hidrosfera, litosfera, atmosfera, biosfera e, possivelmente, a duração da criação das matérias-primas para confecção de produtos usados no dia-a-dia e descartados rapidamente.

Toledo et al. (2003) apresentaram uma proposta pedagógica a qual afirma que, para se ter uma relação harmoniosa entre o ser humano e a natureza, é necessário que aquele tome conhecimento de seu lugar perante a natureza e saiba utilizar o que ela proporciona. Baseando-se nesta informação, os autores afirmaram que no ensino de qualquer nível, o docente deve apresentar aos alunos, de forma multidisciplinar, a dinâmica da evolução da natureza levando em conta o tempo geológico levado para tal acontecimento. Seguindo esta forma de ensino, é possível levar a sociedade a fazer um uso consciente de materiais retirados da natureza a fim de reduzir o impacto gerado pelas ações antropogênicas.

O ensino de Geociências juntamente com os trabalhos práticos, além de permitirem um desenvolvimento cognitivo nos alunos (Compiani 2005, p.15), também:

(...) estimulam o desenvolvimento de conhecimentos como: intuição e desenvolvimento da linguagem visual, apreciação de formas e estética, raciocínio e representação espacial, raciocínios de causalidade e a narrativa envolvida nos discursos históricos da Geologia/Geociências.

No entanto, o estudo realizado por Oliveira \& Viviani (2001) apontou que o uso de experimentação em conteúdos de Geociências, em comparação com as outras matérias, é pouco frequente, logo, parece necessário uma maior introdução de experimentação na área, já que o uso de experimentos de Geociências é extremamente importante para que o aluno consiga visualizar, compreender e se interessar por algum conteúdo já que muitos tópicos dessa disciplina transpõem a escala humana de existência, levando milhares ou milhões de anos para ocorrer, o que os tornam abstratos.

Baseando-se nos papéis que o experimento pode ter em uma aula e na importância de sua aplicação em aulas de Geociências, ficam as seguintes questões: Por qual experimentação o docente deve optar a fim de ter uma melhor efetividade na aprendizagem dos alunos: a investigativa ou a ilustrativa? Qual delas ajuda o aluno a ter uma ideia melhor de como tudo ocorre e ter uma compreensão lógica e correta? O experimento do conteúdo abstrato ou do tema cotidiano influencia no entendimento? Existe uma forma que tenha como objetivo específico o aprendizado ou o raciocínio lógico? Estas questões compõem o cerne do presente estudo.

Para realizar a pesquisa, foram usados dois tipos de conteúdos: conteúdo abstrato e conteúdo cotidiano. O conteúdo abstrato é um conteúdo que não é possível para o aluno observar cotidianamente, seja pela duração do evento ou escala geográfica. 
O conteúdo abstrato aqui relatado é a formação de relevos. Analisando o PCN de Ciências Naturais do Ensino Fundamental para o terceiro e o quarto ciclo, é possível notar que não existe uma relação muito forte de visão de formação de relevo e as Ciências da Natureza. Existe um ou outro fato que faz com que o relevo seja citado durante as aulas, mas não tratado como um assunto principal, bem como sua relação com a distribuição de seres vivos em seus habitats e adaptações fisiológicas de cada grupo em diferentes altitudes. É exemplo:

A estrutura interna da Terra é também dinâmica, originando vulcões, terremotos e distanciamento entre os continentes, o que altera constantemente o relevo e a composição das rochas e da atmosfera, seja pela deposição de gases das erupções, seja por mudanças climáticas drásticas, como glaciações e degelos (Brasil 1997, p.41)

O conteúdo em questão é tratado também na disciplina de Geografia, o que acaba fragmentando o ensino deste assunto em duas disciplinas. A partir de ocorrências naturais, o PCN traz com este conteúdo a formação de relevos.

O estudo do vulcanismo, dos terremotos, com suas consequências muitas vezes catastróficas para a sociedade, poderá ser explorado como detonador de uma discussão dos processos que originaram as diferentes formas do relevo. (Brasil 1998, p.61)

Já o conteúdo cotidiano é um conteúdo que engloba eventos que o aluno é capaz de observar por ocorrerem rapidamente, dentro da escala humana. É o caso dos eventos de erosão, o outro tema abordado durante o desenvolvimento do presente trabalho. O PCN trabalha a ideia de erosão mostrando possíveis perguntas a serem feitas aos alunos durante a aula e, a partir daí, iniciar o ensino do conceito e a ocorrência deste fenômeno.

Mas, o que acontece quando a chuva cai sobre o solo descoberto de vegetação? E quando cai sobre solo coberto por mata ou plantação? Há alguma diferença?

As crianças podem levantar suposições e testá-las com experimentos e observações. Deste modo, é possível o professor encaminhar a noção de que o solo descoberto recebe a água da chuva com maior impacto que solos cobertos nos quais as raízes dos vegetais formam redes que impedem a desagregação do solo. Em consequência, a água carrega partículas de solo em maior quantidade na primeira situação. Por meio da comparação dessas situações torna-se viável elaborar a ideia de erosão, considerando-se que esse fenômeno ocorre com mais intensidade nos ambientes transformados pelo homem, em vista do desmatamento por ele realizado (Brasil 1998, p.61).

Este trabalho teve como objetivo principal analisar o aprendizado dos alunos a partir da aplicação das experimentações investigativas e ilustrativas, tanto para um tema cotidiano, quanto para um tema abstrato que comumente é tratado de forma fragmentada, seja por seu contexto espacial, como pelo sua extensao temporal. Em seguida, comparou-se a diferença da efetividade entre elas. Ao final deste estudo, são apresentados dados que poderão servir para demonstrar o impacto de cada tipo de experimentação e que, em conjunção com outros dados da literatura, ajudarão os docentes a prepararem aulas de Geociências mais eficientes, com metodologias pluralizadas que se adaptem a cada tema das aulas, onde o conteúdo não seja memorizado pelo aluno, mas sim entendido com a ajuda de um modelo criado, visto e discutido em sala de aula.

\section{Metodologia}

\section{Contexto e participantes}

O presente estudo foi realizado na cidade de Brasília, DF, no primeiro semestre de 2015. A escola escolhida foi o Centro de Ensino Fundamental 03 (CEF-03) localizado na Asa Sul do Plano Piloto.

A pesquisa para este trabalho teve a participação de quatro turmas de $6^{\circ}$ ano (antiga $5^{\text {a }}$ série) do Ensino Fundamental ao longo de três semanas. As turmas participantes foram $6^{\circ} \mathrm{A}, 6^{\circ} \mathrm{B}, 6^{\circ} \mathrm{C}, 6^{\circ} \mathrm{D}$. As aulas foram realizadas pelo autor deste estudo sempre acompanhado pelas professoras das turmas. A faixa etária dos alunos foi de 10-12 anos.

A quantidade de alunos participantes foi de 73 alunos para a experimentação relacionada ao tema erosão e 76 alunos para a experimentação relacionada ao tema formação de relevo. A diferença entre os alunos participantes foi dada pela ausência de alguns nos dias das aulas. $\mathrm{Na}$ aula de erosão estiveram presentes 19 alunos na turma A, 19 na turma B, 15 na turma C e 20 na turma D. Na aula de formação de relevo, estiveram presentes 20 alunos na turma 
A, 19 na turma B, 17 na turma C e 20 na turma D.

\section{Escolha dos temas trabalhados}

A escolha dos temas das aulas tomou-se como pressuposto que atualmente os alunos precisam ter a consciência da relação entre o homem e a natureza (Bacci 2009) e uso de recursos naturais de forma menos prejudicial ao meio ambiente. Através do Ensino de Geociências é possível fazer com que o aluno compreenda as consequências das atividades humanas na natureza, sendo possível a diminuição da degradação do meio ambiente (Toledo et al. 2005). Dentre os temas escolhidos, um pode ser observado dentro da escala de tempo humana (assunto cotidiano) e outro fora dessa mesma escala (assunto abstrato). A partir daí, tomou-se como assunto cotidiano o fenômeno de Erosão e o abstrato a formação de relevo. Para que não houvesse resultados tendenciosos, os dois temas foram tratados com experimentação investigativa e ilustrativa dentro de quatro turmas do $6^{\circ}$ ano, antiga $5^{\text {a }}$ série, alternando os conteúdos entre as turmas. Tomou-se como base a escolha do $6^{\circ}$ ano pelos conteúdos citados estarem no currículo dessa série como definido pelos Parâmetros Curriculares Nacionais de Ensino de Ciências do Ensino Fundamental.

\section{Materiais utilizados para realização dos experimentos}

Para a realização do experimento de erosão foi utilizado um vaso com plantas, representando um modelo de um solo com vegetação, e um recipiente completamente cheio de terra que serviu como modelo de solo nu, além de duas travessas de vidro para a captação da água, e uma garrafa PET com água para simular a precipitação da chuva. $\mathrm{O}$ segundo experimento, sobre a formação de relevo, foi realizado utilizando somente duas tábuas de madeira para demonstrar as placas tectônicas e massinha de modelar, que simulou o dobramento da crosta.
Nenhum dos experimentos é obra original dos autores deste trabalho e foram encontradas na Internet em diversas páginas sobre ensino de Geociências. Foram escolhidos experimentos fáceis de serem realizados no tempo de uma aula convencional (50 minutos ou uma hora-aula) e que usam materiais de baixo custo e fácil acesso, além de não precisarem de laboratórios para sua realização. Houve cuidado com o experimento de erosão para que não sujasse a sala ou carteiras com terra e água.

\section{Procedimentos para realização dos experimentos}

Cada turma teve os dois tipos de experimentação realizados em momentos diferentes nas aulas e foram desenvolvidos de forma intercalada entre as turmas. Enquanto duas delas iniciaram a aula com a experimentação para depois partirem para a aula teórica, as outras duas começaram com a aula teórica partindo então para a experimentação ilustrativa (Tab. 1).

\section{Experimentação Investigativa}

Para iniciar o experimento de erosão, o vaso com plantas foi inclinado dentro de uma travessa e o outro recipiente somente com terra inclinado em outra travessa. A garrafa PET cheia de água serviu como modelo de uma nuvem carregada e prestes a precipitar. Para melhor compreensão do que estava acontecendo ali, foi explicado aos alunos que eles estavam observando modelos de solos e a precipitação de uma nuvem. Metade do conteúdo da garrafa foi despejado sobre o modelo de solo sem vegetação e foi pedido para que os alunos observassem o que tinha acontecido, seguido de perguntas sobre o que eles observaram. Com as respostas obtidas para o primeiro modelo, a outra metade de água foi despejada sobre o solo com vegetação e, de novo, perguntou-se o que os alunos observaram. Dadas as respostas, as diferenças entre os solos foram contrastadas com base em perguntas, bem como o que havia ocorrido de diferente durante

Tabela 1. Organização das atividades desenvolvidas no presente estudo.

\begin{tabular}{|c|c|c|c|c|}
\hline & Turma A & Turma B & Turma C & Turma D \\
\hline $\begin{array}{l}\text { Experimento } \\
\text { erosão } \\
\text { (cotidiano) }\end{array}$ & $\begin{array}{c}\text { Teoria } \\
\boldsymbol{\nabla} \\
\text { Experimento } \\
\text { (aula ilustrativa) }\end{array}$ & $\begin{array}{c}\text { Teoria } \\
\boldsymbol{\nabla} \\
\text { Experimento } \\
\text { (aula ilustrativa) }\end{array}$ & $\begin{array}{c}\text { Experimento } \\
\nabla \\
\text { Teoria } \\
\text { (aula investigativa) }\end{array}$ & $\begin{array}{c}\text { Experimento } \\
\nabla \\
\text { Teoria } \\
\text { (aula investigativa) }\end{array}$ \\
\hline $\begin{array}{l}\text { Experimento } \\
\text { formação de } \\
\text { relevo } \\
\text { (abstrato) }\end{array}$ & $\begin{array}{c}\text { Experimento } \\
\nabla \\
\text { Teoria } \\
\text { (aula investigativa) }\end{array}$ & $\begin{array}{c}\text { Experimento } \\
\nabla \\
\text { Teoria } \\
\text { (aula investigativa) }\end{array}$ & $\begin{array}{c}\text { Teoria } \\
\nabla \\
\text { Experimento } \\
\text { (aula ilustrativa) }\end{array}$ & $\begin{array}{c}\text { Teoria } \\
\nabla \\
\text { Experimento } \\
\text { (aula ilustrativa) }\end{array}$ \\
\hline
\end{tabular}


a precipitação nos solos. Com as indagações, os conceitos construídos a partir da experimentação foram anotados no quadro. Com uma aula expositiva dialogada baseada na experimentação e com o uso de desenhos, os alunos foram guiados através dos conceitos ditos corretos.

Para demonstrar o segundo evento (formação de relevo) foram usadas duas tábuas de madeira e quatro pedaços de massinha, sendo duas frações postas sobre as outras duas. As massinhas foram deixadas na posição horizontal, com o maior comprimento entre as duas tábuas. Novamente, para melhor entendimento dos alunos, foi informado que tratava-se de um modelo de local de choque entre placas tectônicas. Após esclarecido, as tábuas de madeira foram aproximadas vagarosamente e a massinha começou a se deformar. Sendo observado tal fenômeno, os alunos foram instigados a criarem suas próprias teorias sobre o que acontecera e novamente guiados através dos conceitos teóricos envolvidos.

\section{Experimentação Ilustrativa}

Para ambos os conteúdos - erosão e formação do relevo -, a aula começou com o conteúdo teórico. Para não ser uma aula cansativa, foi utilizada aula expositiva dialogada, baseada nos conhecimentos prévios dos alunos. Com a utilização do quadro, os conceitos foram anotados e desenhos foram feitos para facilitar a visualização dos fenômenos. Ao terminar o conteúdo, os experimentos foram aplicados para corroborar a teoria estudada na aula.

\section{Procedimentos para a análise de dados}

Para comparar a efetividade das experimentações foram utilizados dois tipos de avaliações. A primeira avaliação foi feita pelo aplicador da aula a partir da observação dos alunos. A segunda avaliação foi um questionário respondido pelos alunos no valor de 10,0 pontos. Aqui estabeleceu-se que o aprendizado eficaz ocorreu a partir de $60 \%$ de absorção de um conteúdo específico, ou seja, o aluno deveria obter nota 6 num critério de avaliação de $0-10$.

A primeira avaliação partiu da observação do autor com um olhar crítico e anotações pós-aula, em relação ao comportamento dos alunos, participação, quantidade de alunos com interesse e argumentos baseados em conhecimentos adquiridos durante a atividade e/ou aula, perguntas durante as aulas baseadas no experimento no caso de experimentação investigativa e perguntas durante o experimento baseadas na aula no caso de experimentação ilustrativa, de forma geral entre as turmas e entre os dois tipos de aulas aplicadas à mesma turma. Os comentários realizados em relação ao comportamento, participação e interesse dos alunos foram curtos e diretos para que houvesse uma forma simples de análise destes dados. Essa avaliação permitiu tirar conclusões de qual experimentação foi mais eficaz para que os alunos fossem mais ativos durante a aula com teorias próprias e que tivessem maior compreensão de como os fenômenos ocorrem.

A segunda avaliação coube aos alunos em forma de questionário, porém não foi aplicada como prova tradicional, para que os alunos não se sentissem pressionados a tirar uma nota alta e isso acabar afetando negativamente o pensamento, raciocínio e forma de resposta dos alunos, podendo gerar algum resultado tendencioso no final do estudo. No entanto foi pedido que o questionário fosse levado a sério, sem consulta no caderno, livro e sem conversar com qualquer colega. A avaliação não influenciou na nota que a professora titular deu para o aluno no bimestre, semestre, ou ainda, ano letivo.

Dentre as questões elaboradas, duas dos questionários de erosão e do questionário de formação de relevo foram consideradas como ponto principal de comparação pelo fato de que estas são diretamente ligadas aos experimentos. As duas questões tiveram valores mais altos que as outras questões. A primeira questão explorada foi a questão 4 da lista de exercícios de erosão. A pergunta foi "A vegetação interfere na erosão?”. Já a segunda questão relacionada ao tema erosão, a questão 5 , os alunos deveriam classificar quatro afirmações em verdadeiro ou falso, entre elas:

- O vento pode causar erosão;

- Vegetação aumenta a erosão;

- Erosão existe em cidades;

- Solo nu (sem vegetação) não sofre erosão.

A primeira questão analisada da lista de exercícios sobre o tema formação de relevo foi a questão 3 , a qual pedia que o aluno explicasse como uma montanha pode ser soerguida. Outra questão de interesse foi a questão 5 , que pedia que o aluno desenhasse e usasse flechas para mostrar como uma montanha pode ser formada.

Foram analisadas também as notas gerais dos questionários para comparação sobre a compreensão 
geral dos temas. Levou-se em consideração que as respostas julgadas parcialmente corretas são positivas para o aprendizado, pois demonstra que os alunos tiveram um entendimento parcial da matéria e compreensão do que o experimento simula. Para que não houvesse dúvidas em relação às perguntas da lista de exercícios, cada pergunta foi lida em voz alta com os alunos, explicando-as o sem dar dicas de possíveis respostas. Permitiu-se sanar eventuais dúvidas que aparecessem em relação ao entendimento das questões.

\section{Resultados e Discussão}

As tabelas 2 e 3 indicam os intervalos das notas obtidas e suas respectivas porcentagens em relação ao tema erosão, quando tratado através da experimentação investigativa e da ilustrativa.

É possível notar o tipo de experimentação não influencia muito na facilidade de o aluno compreender algo abstrato, já que tanto na experimentação Tabela 2. Relação das notas e alunos para o tema erosão.

\begin{tabular}{|c|c|c|c|c|c|}
\hline \multicolumn{6}{|c|}{ Tema Erosão } \\
\hline \multicolumn{6}{|c|}{ Experimentação Ilustrativa } \\
\hline Nota & Turma A & Turma B & \multirow{7}{*}{ Porcentagem } & Turma A & Turma B \\
\hline $10-8.0$ & 3 & 9 & & $15,79 \%$ & $47,37 \%$ \\
\hline $7.9-6.0$ & 7 & 5 & & $36,84 \%$ & $26,32 \%$ \\
\hline $5.9-4.0$ & 5 & 2 & & $26,32 \%$ & $10,53 \%$ \\
\hline $3.9-2.0$ & 3 & 3 & & $15,79 \%$ & $15,79 \%$ \\
\hline $1.9-0.0$ & 1 & 0 & & $5,26 \%$ & $0,00 \%$ \\
\hline Total: & 19 & 19 & & $100 \%$ & $100 \%$ \\
\hline \multicolumn{6}{|c|}{ Experimentação Investigativa } \\
\hline Nota & Turma C & Turma D & \multirow{7}{*}{ Porcentagem } & Turma C & Turma D \\
\hline $10-8.0$ & 4 & 3 & & $26,67 \%$ & $15,00 \%$ \\
\hline $7.9-6.0$ & 1 & 5 & & $6,67 \%$ & $25,00 \%$ \\
\hline $5.9-4.0$ & 5 & 4 & & $33,33 \%$ & $20,00 \%$ \\
\hline $3.9-2.0$ & 3 & 6 & & $20,00 \%$ & $30,00 \%$ \\
\hline $1.9-0.0$ & 2 & 2 & & $13,33 \%$ & $10,00 \%$ \\
\hline Total: & 15 & 20 & & $100 \%$ & $100 \%$ \\
\hline
\end{tabular}

Tabela 3. Relação das notas e alunos para o tema formação de relevo.

\begin{tabular}{|c|c|c|c|c|c|}
\hline \multicolumn{6}{|c|}{ Tema Formação de Relevo } \\
\hline \multicolumn{6}{|c|}{ Experimentação Investigativa } \\
\hline Nota & Turma A & Turma B & \multirow{7}{*}{ Porcentagem } & Turma A & Turma B \\
\hline $10-8.0$ & 0 & 0 & & $0,00 \%$ & $0,00 \%$ \\
\hline $7.9-6.0$ & 2 & 5 & & $10,00 \%$ & $26,32 \%$ \\
\hline $5.9-4.0$ & 6 & 2 & & $30,00 \%$ & $10,53 \%$ \\
\hline $3.9-2.0$ & 9 & 3 & & $45,00 \%$ & $15,79 \%$ \\
\hline $1.9-0.0$ & 3 & 9 & & $15,00 \%$ & $47,37 \%$ \\
\hline Total: & 20 & 19 & & $100 \%$ & $100 \%$ \\
\hline \multicolumn{6}{|c|}{ Experimentação Ilustrativa } \\
\hline Nota & Turma C & Turma D & \multirow{7}{*}{ Porcentagem } & Turma C & Turma D \\
\hline $10-8.0$ & 2 & 1 & & $11,76 \%$ & $5,00 \%$ \\
\hline $7.9-6.0$ & 4 & 3 & & $23,53 \%$ & $15,00 \%$ \\
\hline $5.9-4.0$ & 2 & 3 & & $11,76 \%$ & $15,00 \%$ \\
\hline $3.9-2.0$ & 5 & 7 & & $29,41 \%$ & $35,00 \%$ \\
\hline $1.9-0.0$ & 4 & 6 & & $23,53 \%$ & $30,00 \%$ \\
\hline Total: & 17 & 20 & & $100 \%$ & $100 \%$ \\
\hline
\end{tabular}
investigativa quanto na experimentação ilustrativa sobre o tema formação de relevo, a porcentagem das notas acima da média foi baixa, com valores de $17,95 \%$ e $27,02 \%$, respectivamente (tab.3).

Analisando as porcentagens obtidas, independentemente do tipo de experimentação realizada (tabs. 2 e 3), é possível observar que a maioria das notas acima de 6 é sobre o tema erosão. Partindo do pressuposto de que é mais fácil compreender um tema quando se é possível observar o fenômeno, ou seja, quando o aluno estuda o meio em que vive (Mahoney \& de Almeida 2005), o tema erosão, que faz parte do cotidiano, acabou mostrando melhores resultados.

No que concerne às questões consideradas chaves para a compreensão do assunto, a figura 1 destaca os resultados obtidos quanto à questão 4 do questionário sobre erosão, apresentando índices refinados relativos às diferentes turmas e ao tipo de experimentação adotada. $\mathrm{O} \mathrm{N}$ amostral para as turmas A, B, C e D correspondem a 19, 19, 15 e 20, respectivamente (Tab. 2).

Ao analisar a efetividade do experimento de erosão (questão 4) pode-se observar que a quantidade de acertos nessa questão é maior nas turmas que tiveram aula com experimentação ilustrativa (Fig. 1). Os gráficos da figura 1 também mostram que, ao somar-se os valores das turmas com um tipo de experimentação $(A+B$ e $C+D)$, resulta que a experimentação investigativa possui $68 \%$ de respostas parcialmente corretas contra $37 \%$ da experimentação ilustrativa, permitindo afirmar que 


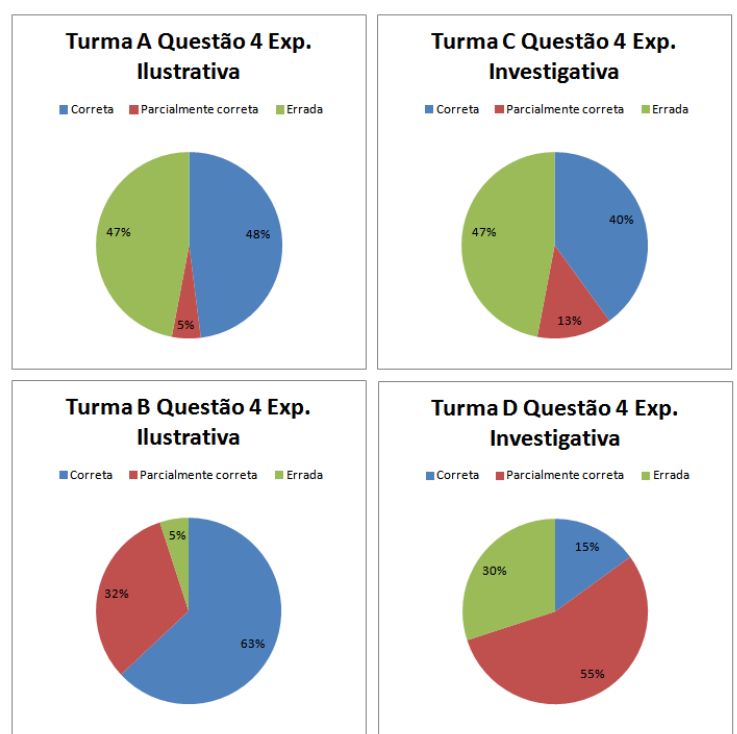

Figura 1. Porcentagem das respostas da questão 4 sobre o tema erosão.

a investigativa é tão boa quanto a ilustrativa em termos de absorção de conhecimento sobre o tema cotidiano. Para deixar claro qual experimentação tem maior efetividade, levou-se em consideração a quantidade de repostas erradas. Novamente, somando os valores de cada experimentação, tem-se um resultado de $52 \%$ de respostas erradas para a experimentação ilustrativa contra $77 \%$ para a experimentação investigativa.

Já os resultados da questão 5 do questionário de erosão, também considerada importante na análise da efetividade da experimentação empregada, são resumidos na figura 2. Nota-se que, quando o experimento é ilustrativo, as porcentagens de respostas corretas são maiores que o dobro daquelas consideradas corretas quando o experimento investigativo é aplicado. Já as respostas parcialmente corretas ganham destaque em comparacação com o experimento investigativo, em relação ao experimento ilustrativo. Desta forma postula-se que, quando o foco foi um assunto cotidiano, o experimento tratado como investigativo teve efetividade, garantido que os alunos absorvessem ou expusessem parcialmente a totalidade do conhecimento, porém, o experimento ilustrativo mostrou-se mais eficaz, demostrando que a grande maioria dos alunos expusessem a resposta considerada correta.

O fato da questão 5 ser de múltipla escolha não pode ser deixado de lado. Este aspecto pode ter influenciado na quantidade de respostas parcialmente corretas, considerando que se o aluno errasse pelo menos uma alternativa, ele acertava parcialmente a questão. Analisando que, além da pior porcentagem de respostas erradas na experimentação ilustrativa é de $53 \%$ e na investigativa é de $13 \%$, é levado em consideração que a investigativa possui mais respostas corretas, então é possível afirmar que os alunos apresentaram maior compreensão da ocorrência do fenômeno através da segunda experimentação.

Considerando as análises voltadas para o outro tema, a formação do relevo, os índices de acerto para a questão 3, cuja resposta, embora ampla, era bastante direta, mostraram-se baixos, independentemente do tipo de experimentação. É possível notar que respostas erradas são, em duas ocasiões, o dobro das corretas, enquanto que nas duas outras situações são superiores, mas não ultrapassam o dobro.

Ainda no que concerne ao experimento de formação de relevo, a questão 5 também foi atentamente analisada, considerando-se todos os aspectos representados nos desenhos (fig. 4). Novamente, o índice de acertos foi superior aos de erro quando a experimentação ilustrativa foi aplicada. No entanto, cabe ressaltar que, embora maior, os índices de acerto não são tão expressivamente superiores ao de erro quanto na questão anterior. Por outro lado, a experimentação investigativa mostrou-se pouco eficaz, já que os índices de acertos foram iguais ou pouco menores que os índices de erros.

No entanto, á válido considerar que os índices demonstrados na figura 5 sobre formação de relevos podem refletir não apenas a efetividade

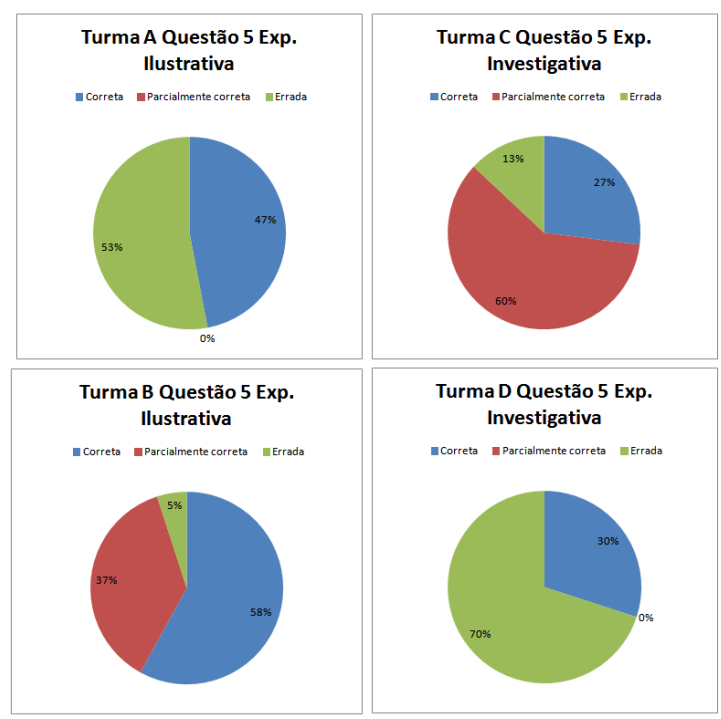

Figura 2. Porcentagem das respostas da questão 5 sobre o tema erosão. 

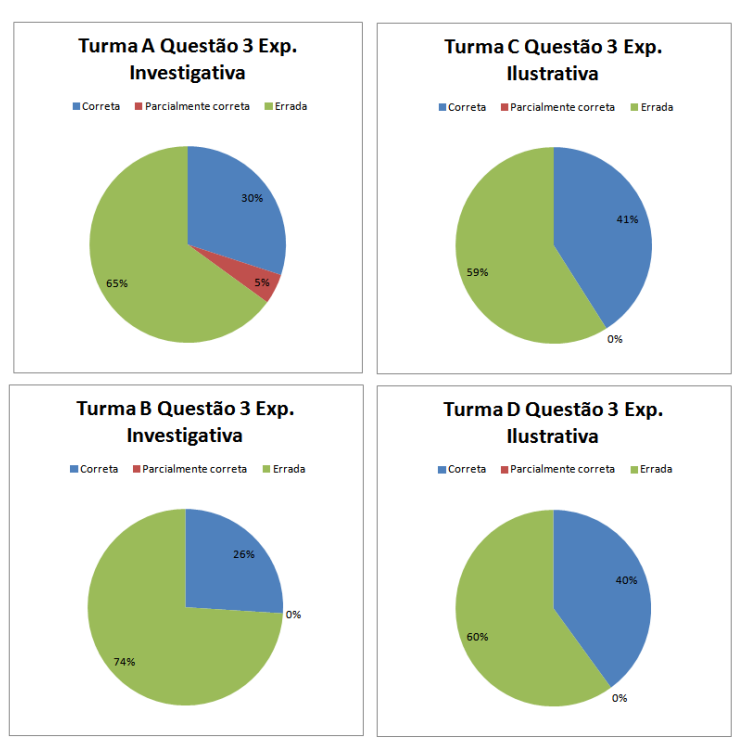

Figura 3. Porcentagem das respostas da questão 3 sobre o tema formação de relevo.

de experimentos na explicação de um tema abstrato, mas também um outro fator, igualmente importante na vida acadêmica dos alunos: a falta do hábito de se expressar na forma de desenhos e gráficos. O baixo rendimento dos alunos em uma questão cuja resposta envolvia expressão na forma de desenho pode estar ligado ao fato de que trata-se de uma resposta pouco convencional, já que o conhecimento sempre lhes é cobrado na forma de palavras e não de formas alternativas, como desenhos. No entanto, essa questão permanece aberta, uma vez que, este não fazia parte dos objetivos do estudo e faltam elementos para uma análise mais profunda.

De um modo geral, é possível notar que a maior efetividade deve-se às experimentações ilustrativas, seja analisando as notas totais ou as notas de questões específicas, e sendo considerado tanto tema cotidiano, como tema abstrato. A experimentação ilustrativa alcançou melhores notas em relação às questões direcionadas ao experimento realizado na aula. Além de mais eficaz em termos relativos a cada turma (tab. 2 e 3 ), a maioria das notas acima da média 6 foi alcançada, em ambos os temas, quando a experimentação ilustrativa foi aplicada (fig. 5).

Analisando as anotações feitas após as aulas e comparando as próprias aulas, percebe-se que a quantidade de alunos com argumentos e interesse na matéria era maior em aulas com experimentação do tipo investigativa. Por estarem, ao que parece, acostumados com aulas tradicionais,

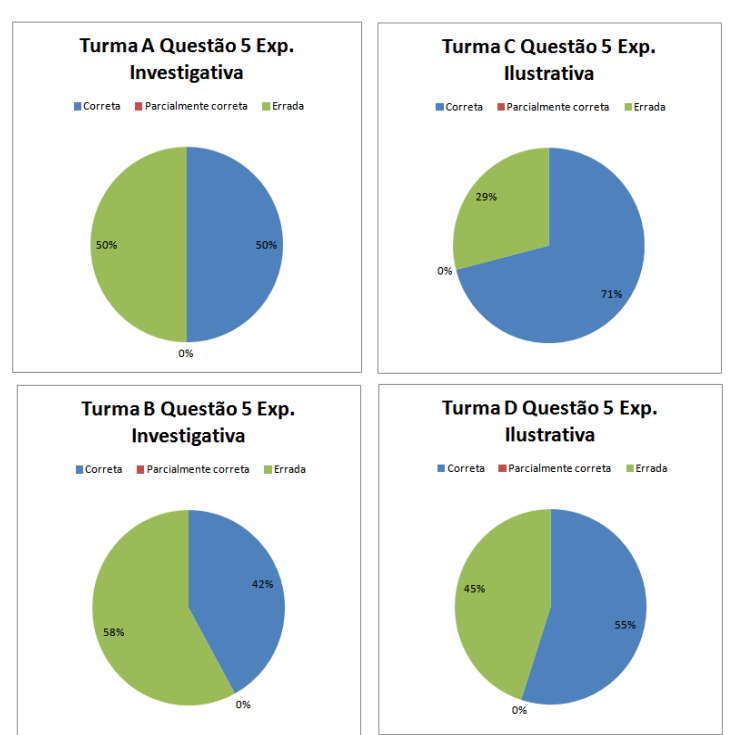

Figura 4. Porcentagem das respostas da questão 5 sobre o tema formação de relevo.

onde não são instigados a falar, a participação era relativamente pequena, mas ainda assim era maior quando observavam o fenômeno antes. No entanto, cabe ressaltar que os alunos, em sua maioria, se interessavam pelo experimento investigativo quanto ilustrativo. Por outro lado, embora a efetividade tenha sido menor, as aulas com experimentação do tipo investigativa, tiveram mais participação dos alunos no sentido de criarem suas próprias hipóteses e argumentos, sobre como e porquê o fenômeno demonstrado ocorre, o que possibilitou uma conversa com opiniões diferentes e visões críticas. Durante a aula com experimentação ilustrativa, os alunos prestavam mais atenção pelo fato de não conhecerem o fenômeno que está sendo tratado na aula, mas assim que observavam o experimento, conseguiam relacionar o conteúdo com o que ocorreu.

\section{Notas acima da média para cada experimentação}

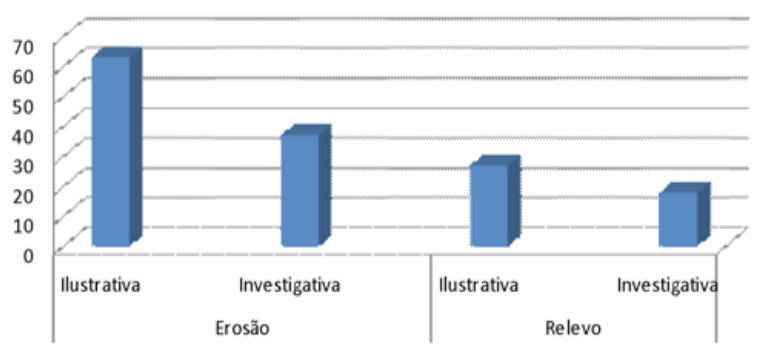

Figura 5. Porcentagem de alunos acima da média para cada tipo de experimentação. 


\section{Conclusão}

Analisando os dados obtidos a partir das avaliações e sobre a participação dos alunos, é possível afirmar que cada experimentação tem suas vantagens. Foi observado que a experimentação investigativa permite aos alunos pensarem por conta própria sobre o tema, o que gera uma discussão saudável para o amadurecimento e visão crítica individual. No entanto, pode ocorrer que a aprendizagem seja limitada, talvez dada pela construção de hipóteses próprias, ou pelo fato de a desconstrução de uma linha de raciocínio equivocada seja uma tarefa difícil. Por outro lado, a experimentação ilustrativa mostrou-se mais eficiente para a aprendizagem e como complemento das aulas teóricas. No entanto não possibilita na mesma intensidade que o aluno pense por si só. Além disso, o estudo também aponta, como esperado, que os alunos têm mais facilidade em compreender um fenômeno que é possível ser observado, ou seja, que ele acompanha por estar dentro da escala humana de tempo ou no mesmo espaço.

Os resultados aqui alcançados mostraram que ambos os experimentos podem ser realizados com efetividade específica e que não existe um que seja melhor. Na verdade, o valor de cada experimentação estará nos objetivos que pretende-se alcançar (maior atenção dos alunos ou maior compreensão do tema) e nos momentos em que serão aplicados. Caso o professor queira uma discussão sobre um conteúdo, nada o impede de utilizar experimentação investigativa para que surjam diferentes hipóteses entre os alunos, assim como a experimentação ilustrativa fornecerá uma prova de que realmente a teoria é verdadeira.

A partir desta pesquisa, sugere-se que, para satisfazer quaisquer dúvidas e gerar bons resultados, deve-se associar os dois tipos de experimentação, que serão uma saída para preencher a lacuna que cada experimentação deixa vazia. Usa-se a experimentação investigativa para chamar a atenção do aluno para a matéria, gerar uma conversa sobre o tópico da aula, seguido de discussão, para, ao fim, chegar-se a uma conclusão coletiva que pode ser complementada com a experimentação ilustrativa.

\section{Agradecimentos}

Os autores agradecem à Faculdade $\mathrm{UnB}$ de Planaltina pela chance de desenvolver o presente projeto; aos professores da Faculdade UnB de Planaltina, Profa. Cynthia Bisinoto e Rodrigo Milani Santucci pelas sugestões que muito ajudaram a melhorar o trabalho; e ao Centro de Ensino Fundamental 03 (Asa Sul, Brasília, DF), em especial à sua diretora, Sheila de Mello e às docentes da disciplina de Ciências Naturais para o Ensino Fundamental, pela permissão e apoio durante o desenvolvimento deste estudo.

\section{Referências}

Azevedo M.C.P.S. 2004. Ensino por investigação: problematizando as atividades em sala de aula. In: Carvalho A.M.P. 2004. Ensino de Ciências. São Paulo: Pioneira Thomson Learning. p.19-33.

Bacci D.C.A. 2009. Contribuição do conhecimento geológico para a Educação Ambiental. Pesquisa em Debate, 6(2):23.

Brasil. 1997. Parâmetros Curriculares Nacionais. Ciências Naturais. Ensino de primeira à quarta série. Brasília: MEC/SEF, 1997. 136 p.

Brasil. 1998. Parâmetros Curriculares Nacionais. Geografia. Ensino de quinta a oitava séries. Brasília: MEC/ SEF, 1998. $156 \mathrm{p}$.

Compiani M. 2005. Geologia/Geociências no Ensino Fundamental e a Formação de Professores. Geologia USP, Publ. Esp., 3:13-30.

Del Pozzo L. 2010. As atividades experimentais nas avaliações dos livros didáticos de Ciências do PNLD. Campinas: Universidade Estadual de Campinas. 150 p. (Dissertação de Mestrado)

Delizoicov D. 1991. Conhecimento, tensões e transições. São Paulo: Faculdade de Educação, Universidade de São Paulo. (Tese de Doutorado)

Francisco Jr W.E., Ferreira L.H., Hartwig D.R. 2008. Experimentação Problematizadora: Fundamentos Teóricos e Práticos para a Aplicação em Sala de Aula de Ciências. Química Nova na Escola, 30:34-41.

Galiazzi M.C., Rocha J.M.B., Schmitz L.C., Souza M.L., Giesta S., Gonçalves F.P. 2001. Objetivos das atividades experimentais no ensino médio: a pesquisa coletiva como modo de formação de professores de Ciências. Ciência E Educação, 7(2):249-263.

Giordan M. 1991. O papel da experimentação no ensino de Ciências. In: Enc. Nac. Pesq. Educ. Ciências, 2, Valinhos. Anais, Assoc. Bras. Pesq. Educ. Ciências, v. 2, p. 43-49.

Laburú C.E., Arruda S.M., Nardi R. 2003. Pluralismo metodológico no ensino de Ciências. Ciência E Educação, 9(2):247-260.

Leite L. 2001. Contributos para uma utilização mais fundamentada do trabalho laboratorial no ensino das ciências. In: Caetano H.V. e Santos M.G. 
2001. Cadernos Didácticos de Ciências. Lisboa: Ministério da Educação, Departamento do Ensino Secundário. p. 77-96. v.1.

Mahoney A.A., Almeida L.R. 2005. Afetividade e processo ensino-aprendizagem: contribuições de Henri Wallon. Psicologia da Educação, 20:11-30.

Mizukami M.G.N. 1986. Ensino: as abordagens do processo. São Paulo: EPU. p.13.

Oliveira N., Soares M.H.F.B. 2010. As atividades de experimentação investigativa em ciência na sala de aula de escolas de ensino médio e suas interações com o lúdico. Encontro Nacional de Ensino de Química, 15, Brasília. Anais, 1.

Rosito B.A. 2000. Construtivismo e ensino de Ciências: reflexões epistemológicas e metodológicas. In: Moraes R. O ensino de ciências e a experimentação. Porto Alegre: EDIPUCRS. p. 195-230. 3 ed.

Toledo M.C.M., Macedo A.B., Machado R., Martins V.T.S., Riccomini C., Santos P.R., Silva M.E.,
Teixeira W. 2003. Projeto Pedagógico do Curso de Licenciatura em Geociências e Educação Ambiental. Geologia USP, Publ. Esp., 3:1-11.

Vasconcelos C., Alencoão A., Ferreira C. 2015. O recurso à modelação no ensino das Ciências: um estudo com modelos geológicos. Ciência $\mathcal{E}$ Educação, 21(1):31-48.

Viviani L.M., Oliveira K.R.de. 2001. Livros de ciências $e$ atividades práticas: concepções e referências a diferentes áreas do conhecimento. In: Enc. Nac. Pesq. Educ. Ciências, 8, Campinas. Anais, Assoc. Bras. Pesq. Educ. Ciências, v. 1. URL: http://www.nutes. ufrj.br/abrapec/viiienpec/resumos/R0633-2.pdf. Acesso 07.07.2014.

Wilsek M.M.G., Tosin J.A.P. 2008. Ensinar e aprender Ciências no Ensino Fundamental com Atividades Investigativas através da resolução de problemas. URL: http://www.diaadiaeducacao.pr.gov.br/portals/ pde/arquivos/1686-8.pdf. Acesso 07.07.2014.

Resumo: A importância de aulas envolvendo diferentes atividades a fim de suprir as lacunas deixadas pelas aulas tradicionais é altamente reconhecida. Uma saída para o método tradicional de ensino é 0 uso de experimentações, as quais, dentre as várias classificações pragmáticas, podem ser divididas em experimentações investigativas, nas quais 0 experimento é realizado anteriormente ao conteúdo teórico, e experimentações ilustrativas, tendo os experimentos realizados após o conteúdo teórico, objetivando provar algum fenômeno estudado. No âmbito das Geociências, são trabalhados desde tópicos relacionados a temas comuns ao cotidiano, mas nem sempre fáceis de serem percebidos, bem como temas abstratos por sua escala espacial e/ou temporal e, neste sentido, as experimentações tornam-se excelentes ferramentas de ensino. No presente trabalho analisou-se a efetividade dos experimentos ilustrativos e investigativos frente a um tema cotidiano (erosão) e outro abstrato (formação de relevo). 0 estudo demonstrou que a experimentação ilustrativa, trabalhada após a teoria, teve maior efetividade tanto quando 0 assunto era abstrato, como quando o tema era cotidiano, ao passo que a experimentação investigativa foi mais eficaz em manter a atenção dos alunos e discussões sobre teorias, independente se 0 assunto fosse mais familiar, quanto abstrato.

Palavras-Chave: Experimentação, aulas práticas, estratégias de ensino, temas abstratos, cotidiano. 